\title{
Personally Oriented Model of Education in Conditions of Informatization
}

\author{
Irina Nazarova \\ Bauman Moscow State Technical University \\ 5/1, 2nd Baumanskaya Street \\ Moscow, Russia 105005 \\ E-mail: nazirrad@yandex.ru
}

\begin{abstract}
Due to the development of information technology, the traditional understanding of higher and professional education, as receiving a some amount of knowledge through the teaching of classical humanitarian and natural science disciplines, is clearly incomplete. Today, the basis of education should be not only studying subjects, but the study itself, that have form the way of thinking, spiritual and moral culture level. The higher education institutions have become the centers of science, centers of personality formation. It seems reasonable to provide comprehensive training to ensure a high level of humanitarian, socio-economic, naturalscientific, general and special professional knowledge assimilation, contributing to the formation of culture and professional ethics of a student.
\end{abstract}

Keywords-modern trends of education; motivation for learning; unassisted work of a student; research work; information culture; education systems; self-education; humanization of education

\section{INTRODUCTION}

The development of modern society directly connected to informatization process. The volume of informational stream, increasing in geometric progression, permeates all spheres of human activity, making society fundamentally "open", and knowledge - accessible. Since new millennium beginning grown up young generation that they actively use the newest Internet technologies (generation Z) [1]. Their representatives highly appreciate computer education, the ability to confidently navigate in virtual space, work with huge information streams. Modern young people openly express and defend their own point of view, they do not accept the traditional monologic manner of communication. This situation requires from russian national high education system seriously adapt the educational process to the changes that have taken place, it requires activation of pedagogical interaction, built in a dialogical mode, creation of fundamentally different, motivated approach to the training of modern students. This implies a transition from the substantive to the personal model in the educational space.

\author{
Olga Khalutornykh \\ Bauman Moscow State Technical University \\ Lomonosov Moscow State University \\ 27/4 Lomonosovsky Ave \\ Moscow, Russia 119192 \\ E-mail: olganik@yandex.ru
}

\section{PRESENTATION ABOUT MODERN TRENDS AND CONTRADICTIONS OF EDUCATION DEVELOPMENT}

The typical installation of traditional teaching system ("subject-containing model") that is prevalent in the teaching practice characterized by enriching with the factual and scientific material. It is oriented to obtaining a linear learning result ("correct" answer" / incorrect" answer), but in fact ignoring the process of perceiving information by the audience (the lecturer read the lecture - students record it down and learn it), that does not allow identify the reasons of proposed training materials ineffective perception. In such a situation, the listeners practically do not have an interest in independent search and mastering of necessary scientific information. The traditional educational model does not set the task of analyzing the decision process, it develops and offers an unambiguous, the only true answer. Whereas today it is much more important to understand why a student has come to an incorrect answer than to assess the answer itself within the usual criterion of "correct" answer / "incorrect" answer".

Modern reality demonstrates the necessity of accepting a palliative information space in the sphere of education, it requires the students' ability development to finding polysemantic solutions. The purpose of training a specialist cannot imply today only studying of a subject itself. The other typical installation of training system ("personal model") emphasizes the development of the student's personal qualities: receptions and forms of thought activity, motivation, decision-making, and professional skills acquisition. In fact, there is a reorientation of education from the studying of existing knowledges to ability of independent information finding. It requires the development of an information culture in the broadest sense of the term. It includes the entire set of skills necessary for a person to work with increasing amounts of information.

To develop in student greater susceptibility to the theory is possible only when mastering it through practice. D. Dewey, one of the founders of pragmatism, proposed to educate and form the "head", "hands" and "body" of a person, not forgetting to emphasize the importance of purposeful business fantasy and imagination. In his theory 
he operates with concept of "socialization of the mind", meaning by this objectivity and the need to adapt a person to the interests of others [2]. It is logical to assume that the key to the realization of this idea lies precisely in the practical plane with it theory should integrate in the process of teaching students.

However, here lies the danger of narrow pragmatism, where the conscious self of man is purely empirical in nature, in effect, moves to the level of reflexes. The modern higher school should orient graduates - professionals not on response, but on responsible action, it is necessary to teach them work in semantic field, anticipating their efforts and results in the value dimension. Integration of personal aspirations with the needs of society is an ideal variant of educational process in higher education schools. Education thereby pushes the horizons of the world mastered by man, unfold new opportunities for him. The practical infinity of the processes of comprehension creates the aspiration of science and scientists to further developing of theory. Understanding is a comprehension of individual being and a transcendental rational principle, that manifests itself in reality, fix the tendency of their both unification, thus revealing a tense dialogue of individual with himself, with the culture created by him [3]. The questions of value comparison of scientific practice becomes priority.

Years of study at the university should be understood and systematically presented as a purposeful process of forming professional readiness for creative activity and continuous professional and cultural growth. And if this is a process, then it must be disclosed as the formation of a professional personality. If this goal is clearly understood by the administration and faculty of the university, then its educational and upbringing activity reaches the required level, where the developing potential of each subject is used.

\section{NECESSITY OF EDUCATION HUMANIZATION}

In the new picture of the world, science and education appear as instruments of human assertion in being, the status and role of the existing methods of cognition and learning change substantially, their historical certainty and limitations are realized an otherwise. Traditional attitude "science - reality" is replaced by the "science-culture" attitude. The thing-real gets its justification in commensurate with the existential-life perspective, truth and value form an ideological integrity. The processes of globalization in society and the humanization of nature determine the unity of the objective and subjective, nature and social history. A distinctive feature of the new (synergetic) scientific thinking is not classical pattern construction, but life scenario projecting, reality modeling, determine of possible development vectors, multivariable being of system we are studying. Now "man", "society", "technology" terms are equivalent, nature is not described by outsiders, indifferent observers, scientific rationality determined by a personal universe and requires solutions of most important humanitarian tasks.

Searching of truth is not for science or truth itself, but for man and humanity both. Professional scientist life turns into free activity that allows us to rethink the nature of knowing subject and the role of subjectivity in cognition. Through the process of interpretation and understanding, the creative function of cognition is realized. Results of interpretation comes into conflict with the standards of rationalization adopted in classical picture of the world, with ordinary ideas, becomes an incentive for the development of ideas about rationality, and about science, and the whole picture of the world.

In conditions like that, a professional should be able quickly switch to new or adjacent types of work, various technologies, but is higher school graduate ready for this today? Often, he is not able to cope with the burden of problems fallen on. Lack of the ability to understand - as the most important characteristic of mental activity, is the cause of his confusion. He thinks and acts fragmentarily, mosaically: he knows something in some areas, he knows how to do something in others. Ability to see the whole problem is beyond the competence of most graduates of universities. Therefore, decision-making procedure and responsibility for the choice made, gets beyond the limits of his capabilities Poorly developed in the student years, the ability to social adaptation leads to inability to live and communicate in the team: graduates, trained to "listen", absolutely do not know how to "hear". Most often in the actions of student, and hence the graduate, does not work the model "as it should be," but just the model "anyhow". This is the biggest shortcoming of all higher education [4].

That problem requires for its solution changes in the entire educational system: technologies, teaching methods, enhancing their effectiveness in developing of individual creative potential. This model actually turn education into a process aimed at solving applied, social, managerial, organizational, technological problems. This way makes it necessary to search for and develop new active forms and methods of teaching, the center of which is the Person.

\section{UNITY OF EDUCATION AND SELF-EDUCATION}

An Unassisted Student's Work (USW) can be considered a sufficiently promising active form of education. It provides the opportunity for the development of student creative thinking within the appropriate organization of educational process. The essence of the USW, foremost, in ability to independently managing his own academic activities. Exactly, manifestation of a special feauters of manager transforms the knowledge acquired in university into a genuine human quality. This suggests that the unassisted work of a student can be considered as a result of all types of educational activities. Additionally, the USW has an educational value: it forms independence not only as a set of skills, but also as a character trait that plays an essential role in the structure of a university graduate personality. Therefore, in the learning process, each course should carefully select material for the unassisted student's work [5]. It requires the student's psychological adjustment to importance of the work that is being done, that is expressed in widening his horizons, increasing his erudition and his professional training quality. 
The convincing argumentation of the teacher should show to student that the results of unassisted working have much importance for deeper mastering of lecture material, implementation of laboratory and course works. USW can provide the effect of continuous learning, if assignments for independent work, given out at the previous courses, to include in the course and diploma designing.

The main types of motivation for unassisted student's work are external, internal and procedural ones. External motivation, that is also called "distant", is most effective, because it is conditioned by the prospects of post-university graduates activity. Internal motivation is determined by the inclinations and abilities of the student to study in this institute. The procedural (educational) motivation is manifested in the student's understanding of usefulness unassisted work performed by him. "The inseparable unity of structural basis procedural and informative content of student's thinking is capable to display complicated differentiated methods of evaluation" [6], to identify the causes of misunderstanding and to make the process of information perception really productive.

The new model of education should also change the system for assessing students knowledge. "The generally accepted systems of intelligence evaluation measure just available level of knowledge and thinking operations of individual, but not reflect specifics of decision process, which is confirm by the data inconsistency about relation between effectiveness of activity and individual cognitive processes indicators. At the same time, the active approach gives theoretical reason for using the characteristics of performed actions as criteria for cognitive process evaluating" [7]. Hereby conducted studies of students' cognitive activity clearly demonstrate that "... a multi-level system for assessing activity results let assessing the possible causes of decline the effectiveness of specific cognitive activities. The predominance of speculative answers in finding the missing details may indicate a violation of the balance of differentiation and integration of cognitive processes, conditioned by the peculiarity of emotional and personal characteristics. The analysis of errors in active approach aspect is an effective tool for optimizing the learning process "[8].

Unassisted work should be planned not only in educational, but also in information and research fields. With no diminishing the significance of each sphere, we note that for the long-term motivation, the highest form of the USW is the Researching Student's Work (RSW), especially if it has an applied orientation. Considering the pragmatic focus of modern education, it must be remembered that the main motivating factor in the student's research work is possibility of achieving success. The involvement of students in scientific research, that conducted at the specialized departments, in scientific centers, laboratories, helps to get success. By combining studies and work in scientific collectives, the student develops his thinking. This process is not just changing of forms and types of thought activity. Here they change, improve during the process of mastering the more and more abstract and generalized information, which is presented in scientific articles, analytical thematic reviews, abstracts, monographs.

\section{CONCLUSION}

Modern education should be aimed at training of a new type specialist, distinguished by global thinking, spiritual culture, capable to creative work at all stages of the life cycle from researching and designing to the development of technology and entrepreneurial activity. This kind of work requires an information culture, including ability to understand the essence of the problem, to find the necessary information in various information sources, required to solve the task.

\section{REFERENCES}

[1] M. Atadjanov. Transitional generation in the modern society: from the generation $X$ to the Internet generation // Scientific herald of the Voronezh State University of Architecture and Civil Engineering. series: social and human sciences. 2015. № 4 (8). from. 69-73.

[2] The modern educational process: state and problems ("round table") // Socis. - M., 2005. - № 4. P. 86-93.

[3] Khalutornykh O.N. ... And the silver cord (a review of the book "The Fates of the Creators of the Russian Science, Philosophical Education, No. 8, 2002. Page 77-79

[4] Nazarova I.R. On new approaches to the modeling of higher education // Humanitarian education in a technical university: the state, problems, prospects. - Moscow: MSTU them. Bauman - 2006.P. 176-187.

[5] Gordenko N.V. The dissertation author's abstract on competition of a scientific degree of the candidate of pedagogical sciences "Formation of academic competencies for university students", Stavropol - 2006 // Library of author's abstracts and dissertations on pedagogics http://nauka-pedagogika.com/pedagogika-13-00-08/dissertaciyaformirovanie -akademicheskih-kompetentsiy-u-studentov-vuzov \# ixzz2kVpx0rY1 (circulation date June 10, 2018)

[6] Bordovskaya N.V. et al. The activity approach to studying the student's research potential // International Journal of Experimental Education No. 1. 2012. P.81

[7] A.N. Leontiev Activity. Consciousness. Personality. M .: The book on demand, 2011, $130 \mathrm{p}$.

[8] Davydova E.Y. Multi-level assessment of cognitive activity as a tool for optimizing the learning process. Anan'evskie readings - 2016: Psychology: yesterday, today, tomorrow: materials of an international scientific conference, October 25-29, 2016, in 2 volumes. Volume 2./cor. Ed. A.V. Shabolas, N.V. Grishina, S.V. Mednikov, D.N. Volkov - St. Petersburg: Aising, 2016. - 460 pp. 